\title{
Serotonergic Integration of Circadian Clock and Ultradian Sleep-Wake Cycles
}

\author{
Hiroyuki Miyamoto, ${ }^{1,2,3,4}$ Eiko Nakamaru-Ogiso, ${ }^{1,5}$ Kozo Hamada, ${ }^{1}$ and Takao K. Hensch ${ }^{2,6}$ \\ ${ }^{1}$ Department of Biomedical Chemistry, Institute of International Health, The University of Tokyo Graduate School of Medicine, Bunkyo-ku, Tokyo 113- \\ 0033, Japan, ${ }^{2}$ Laboratory for Neuronal Circuit Development and ${ }^{3}$ Laboratory for Neurobiology of Synapse, RIKEN Brain Science Institute, 2-1, Hirosawa, \\ Wako-shi, Saitama 351-0198, Japan, ${ }^{4}$ Precursory Research for Embryonic Science and Technology (PRESTO), Japan Science and Technology Agency (JST), \\ Saitama 332-0012, Japan, ${ }^{5}$ Department of Biochemistry and Biophysics, School of Medicine, University of Pennsylvania, Philadelphia, Pennsylvania 19104, \\ and ${ }^{6}$ Center for Brain Science, Department of Molecular Cellular Biology, Harvard University, Cambridge, Massachusetts 02138
}

In mammals, the suprachiasmatic nucleus (SCN) of the hypothalamus generates a $24 \mathrm{~h}$ rhythm of sleep and arousal. While neuronal spiking activity in the SCN provides a functional circadian oscillator that propagates throughout the brain, the ultradian sleep-wake state is regulated by the basal forebrain/preoptic area (BF/POA). How this SCN circadian oscillation is integrated into the shorter sleep-wake cycles remains unclear. We examined the temporal patterns of neuronal activity in these key brain regions in freely behaving rats. Neuronal activity in various brain regions presented diurnal rhythmicity and/or sleep-wake state dependence. We identified a diurnal rhythm in the BF/POA that was selectively degraded when diurnal arousal patterns were disrupted by acute brain serotonin depletion despite robust circadian spiking activity in the SCN. Local blockade of serotonergic transmission in the BF/POA was sufficient to disrupt the diurnal sleep-wake rhythm of mice. These results suggest that the serotonergic system enables the BF/POA to couple the SCN circadian signal to ultradian sleep-wake cycles, thereby providing a potential link between circadian rhythms and psychiatric disorders.

\section{Introduction}

The suprachiasmatic nucleus (SCN) of the hypothalamus regulates a broad range of biological and behavioral rhythms, including hormonal secretion, metabolism, neuronal firing, locomotor activity, and sleep-wake cycles (Mistlberger, 2005; Maywood et al., 2006; Saper et al., 2010). Autonomous neuronal spiking occurs with $\sim 24$ h periodicity in the SCN and serves as an essential signal for circadian activity (Inouye and Kawamura, 1979; Schwartz et al., 1987; Ralph et al., 1990; Colwell, 2011), but the mechanism by which the rest of the brain synchronizes with the SCN clock remains unclear.

To sustain the circadian sleep rhythm, the ultradian sleepwake cycle must be linked to circadian SCN activity. Sleep-active or wake-active neurons are found in the basal forebrain and preoptic area (BF/POA), both of which are located near the SCN, and

Received Feb. 19, 2012; revised Aug. 15, 2012; accepted Aug. 29, 2012.

Author contributions: H.M. and E.N.-0. designed research; H.M. and K.H. performed research; E.N.-O. contributed unpublished reagents/analytic tools; H.M. and K.H. analyzed data; H.M., E.N.-O., and T.K.H. wrote the paper.

This work was funded by RIKEN Brain Science Institute (T.K.H.), Grant-in-Aid for Scientific Research (C) (90312280; H.M.), Grant-in-Aid for Young Scientist (B) (17700374; H.M.), and JST PRESTO programs (H.M.). We are grateful to Prof. K. Takai, Prof. K. Kita, and Dr. Y. Yoshihara for support and our laboratory members for helpful discussion.

The authors declare no competing financial interests.

Correspondence should be addressed to Dr. Hiroyuki Miyamot, Laboratory for Neurobiology of Synapse, RIKEN Brain Science Institute, 2-1 Hirosawa, Wako-shi, Saitama 351-0198, Japan, E-mail:miyamoto@brain.riken.jp; or Dr. Eiko Nakamaru-0giso, 207B Anatomy-Chemistry Building, 3620 Hamilton Walk, Philadelphia, PA 19104. E-mail: eikoo@mail.med.upenn.edu.

K. Hamada's present address: Laboratory for Developmental Neurobiology, RIKEN Brain Science Institute, 2-1, Hirosawa, Wako-shi, Saitama 351-0198, Japan.

DOI:10.1523/JNEUROSCI.0793-12.2012

Copyright $\odot 2012$ the authors $\quad 0270-6474 / 12 / 3214794-10 \$ 15.00 / 0$ the stimulation or lesion of these structures alters the sleep-wake architecture (Jones, 2005; Huang et al., 2007; Takahashi et al., 2009). Despite great advances in elucidating the genetic and molecular circadian mechanisms functioning within SCN cells (Takahashi et al., 2008), precisely how this SCN activity controls the circadian pattern of shorter sleep-wake cycles remains unclear, partly because of the many brain regions and pathways that are involved in the regulation of behavioral state (Deurveilher and Semba, 2008; Saper et al., 2010).

Serotonergic (5-hydroxytryptamine, 5-HT) neurons are located in the dorsal and median raphe nuclei of the brainstem. These neurons innervate the entire brain, including the SCN (Morin and Allen, 2006) and BF/POA (Deurveilher and Semba, 2008), and they affect neuronal excitability via various types of 5-HT receptors. Consequently, serotonin neurons have been implicated in the regulation of multiple brain regions and physiological processes, including sleep and arousal (Frank et al., 2002; Popa et al., 2005; Monti and Jantos, 2008). We recently observed that acute depletion of brain 5-HT leads to a disruption of diurnal sleep-wake cycles and locomotor activity in rats (NakamaruOgiso et al., 2012). Here, we examine the physiological processes underlying circadian organization in vivo before and during 5-HT depletion.

To investigate the functional link between circadian rhythms and ultradian sleep-wake cycles, we continuously recorded extracellular neuronal firing (multi-unit activity, MUA) (Nishihara et al., 1994; Yamazaki et al., 1998; Nakamura et al., 2011) in several key brain regions involved in sleep-wake regulation in behaving rats or mice. Our results indicate that the SCN circadian signal is integrated in the $\mathrm{BF} / \mathrm{POA}$ via the serotonergic system. 


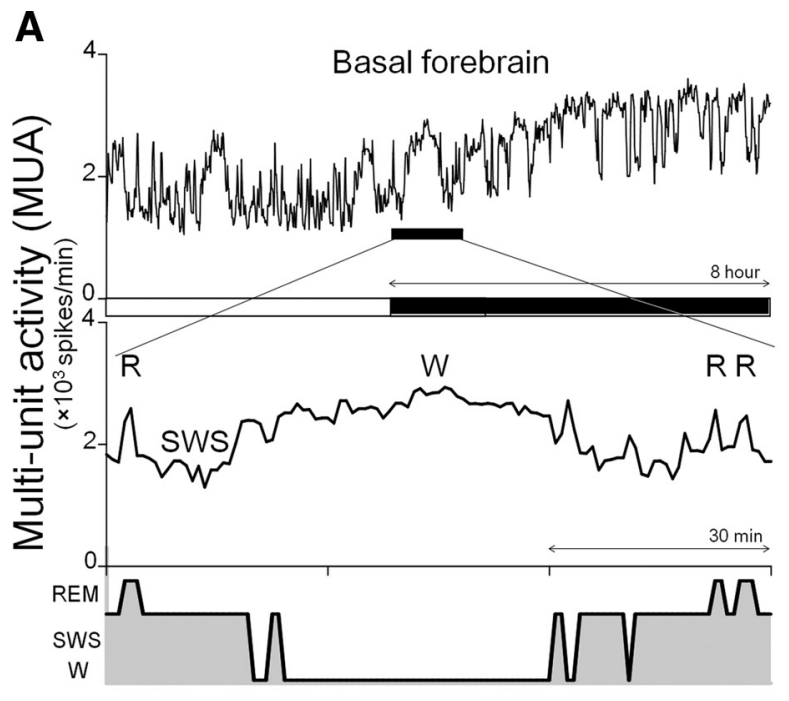

B
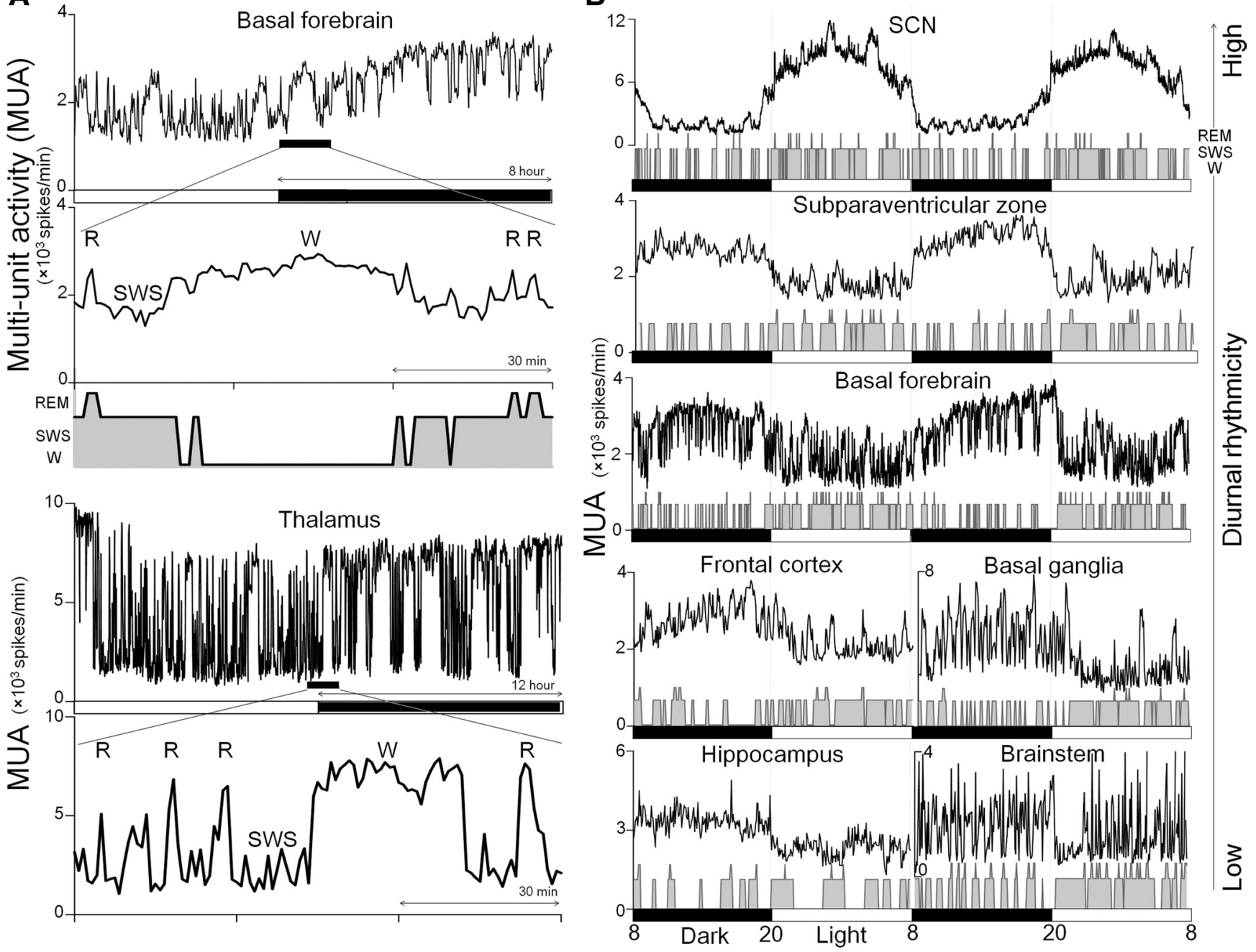

Figure 1. Diurnal and behavioral state-dependent neuronal activities in the brain. $A$, Marked state dependence of neuronal activity (multi-unit activity or MUA) in the rat basal forebrain (medial septum/diagonal band of Broca; top panel, $14 \mathrm{~h}$ recording; middle panel, $1.5 \mathrm{~h}$ expanded recording denoted by horizontal bar in the top panel; bottom panel, hypnogram) and thalamus (centrolateral thalamic nucleus; top panel, $24 \mathrm{~h}$ recording; bottom panel, $1.5 \mathrm{~h}$ expanded recording). Note the elevated neuronal activities associated with waking (W) or rapid eye movement sleep (R). SWS indicates slow-wave sleep. B, Daytime-dominant MUA rhythm in the SCN (top) and night-dominant MUA rhythm in the subparaventricular zone, basal forebrain (medial septum/diagonal band of Broca), prefrontal cortex, basal ganglia (caudate putamen), hippocampus (A1 region, and brainstem (pontine reticular nucleus pars oralis) of a freely behaving rat; 12:12 h light:dark cycle: light period (white bar), 8 A.M.-8 P.M.; dark period (black bar), 8 P.M.-8 A.M.. Hypnograms are shown for each recording site. Note the large diurnal amplitude in the SCN and prominent ultradian sleep-wake activity in the thalamus and brainstem.

\section{Materials and Methods}

Animals (rat/mouse). All experiments were performed under the approval of the local animal care/review committees of the University of Tokyo and RIKEN Brain Science Institute. Full-grown male Sprague Dawley rats (at least 12 weeks of age, $350 \mathrm{~g}$ at the time of surgery; Japan SLC) and C57 BL/6 mice ( $>8$ weeks of age; $30 \mathrm{~g}$ at time of surgery; Japan SLC) were used in this study. They were housed $\left(25^{\circ} \mathrm{C}, 55 \%\right.$ humidity) under 12 h light (8 A.M.-8 P.M.)/12 h dark (8 P.M.-8 A.M.) lighting conditions (200 lux at cage level).

Sleep-wake state (rat). Behavioral states of rats were assessed using electroencephalogram (EEG) and electromyogram (EMG) recordings. Bipolar EEG electrodes consisting of two stainless steel wires were placed on the dura over the frontal cortex $(3.0 \mathrm{~mm}$ anterior to the bregma, 1.5 $\mathrm{mm}$ lateral to the midline). For EMG recordings, two stainless steel wires were inserted into the neck muscle. EEG and EMG signals, which were continuously recorded throughout the experiments, were amplified, bandpass filtered $(0.5-30 \mathrm{~Hz})$ and sampled at $100 \mathrm{~Hz}$. Using EEG power spectra analyses (BIMUTAS, Kissei Comtec), three vigilance stateswaking (W), slow-wave sleep (SWS), and rapid eye movement sleep (REM) - were determined visually based on standardized EEG/EMG criteria for rodents (Miyamoto et al., 2003).
Neuronal activity recording (rat). Compared with mice, rats are more suitable for implantation of multiple MUA electrodes because of their larger body size. Local in vivo neuronal activity (MUA) was obtained by bipolar recordings with contiguously aligned Teflon-coated platinumiridium wires (bare diameter, $125 \mu \mathrm{m}$; AM Systems) (Nishihara et al., 1994). The positions were determined using the following parameters: anteroposterior (AP), anterior to bregma; mediolateral (ML), lateral to the midline; dorsoventral (DV), depth from the dura; and the angle in the coronal plane. The electrodes were inserted into the brain and aimed at the suprachiasmatic nucleus (AP, $-1.1 \mathrm{~mm}$; ML, $1.1 \mathrm{~mm}$; DV, $8.8 \mathrm{~mm}$ depth; angle, $6^{\circ}$ ), subparaventricular zone (AP, $-1.3 \mathrm{~mm}$; ML, $1.2 \mathrm{~mm}$; DV, $8.5 \mathrm{~mm}$; angle, $6^{\circ}$ ), frontal cortex (AP, 3.0; ML, 1.5; DV, $1.1 \mathrm{~mm}$ ), centrolateral thalamic nucleus (AP, $-3.14 ; \mathrm{ML}, 2.1 ; \mathrm{DV}, 5.26 \mathrm{~mm}$; angle, $8^{\circ}$ ), medial septum/diagonal band (AP, 0.48; ML, 1.10; DV, $7.1 \mathrm{~mm}$; angle, $8^{\circ}$ ), substantia innominata (AP, $-0.92 ; \mathrm{ML}, 2.5 ; \mathrm{DV}, 8.4 \mathrm{~mm}$ ), preoptic area (AP, -0.6 ; ML, 1.2; DV, $8.5 \mathrm{~mm}$; angle, $2^{\circ}$ ), pontine reticular nucleus (oral part) (AP, -8.0; ML, 2.2; DV, $7.2 \mathrm{~mm}$; angle, $6^{\circ}$ ), caudate putamen (AP, 0.70; $\mathrm{ML}, 2.8$; DV, $5.2 \mathrm{~mm}$ ), and hippocampal CA1 region (AP, -3.6; ML, 1.4; DV, $2.61 \mathrm{~mm}$ ).

Rats were allowed at least 1 week to recover from the surgery, after which their electrodes were connected to head-stage buffer amplifiers 
A
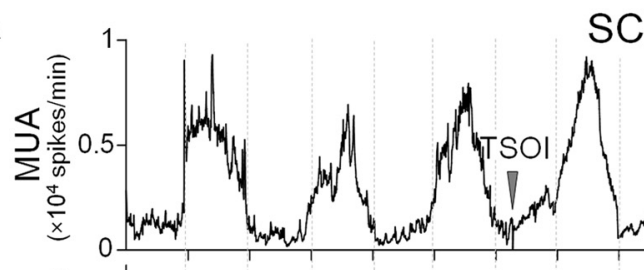

SCN

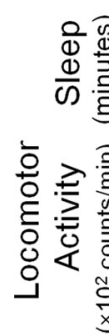

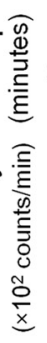

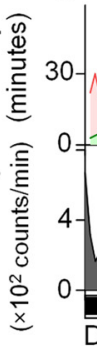

C MUA

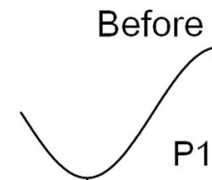$$
\frac{\text { T1 }}{\text { Light }}
$$

P1

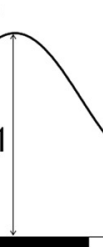

TSOI
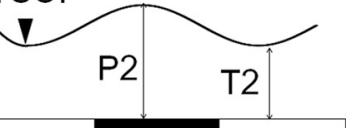

Sleep

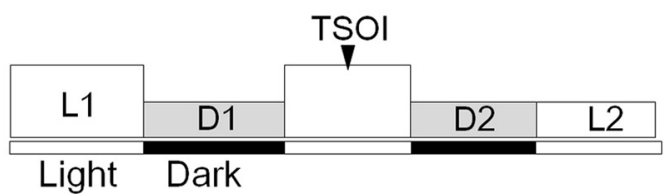

After

D
B

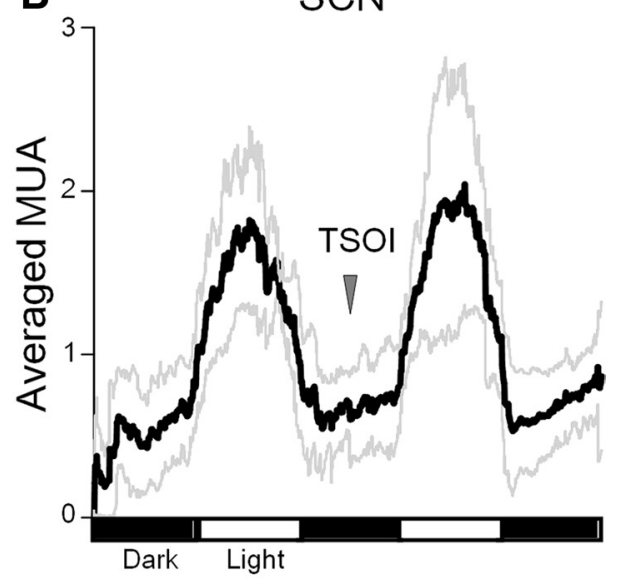

SWS

E

SCN
*

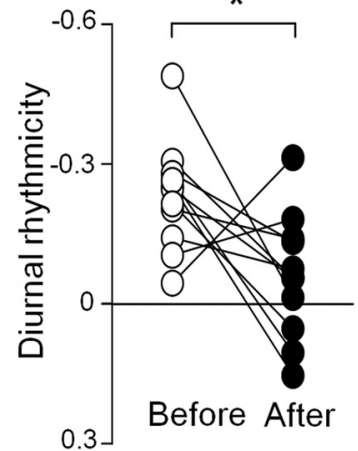

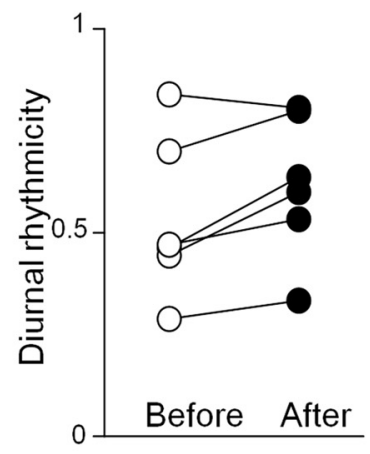

Figure 2. Persistent SCN oscillations in the absence of a diurnal sleep-wake rhythm upon acute depletion of brain 5-HT. A, The SCN circadian MUA is preserved under constant darkness, whereas the circadian sleep rhythm and locomotor activity are severely disrupted following 5-HT depletion (arrowheads, TSOI, 20 units i.p.). MUA, hourly sleep time (minutes per hour), and locomotor activity were simultaneously recorded from the same rat. Note that the light:dark cycle was switched to constant darkness before TSOl injection. Magenta trace, SWS; green trace, REM (middle panel). $\boldsymbol{B}$. Average of normalized MUA rhythms in the SCN (mean $\pm S D, n=6$ ). The MUA at each time point was normalized by the total number of spikes before or after TSOl injection (2.5 days), and the MUAs were then averaged. Black/white bars, 12:12 h dark/light phase. $\boldsymbol{B}$ includes data from $\boldsymbol{A}$ (under light: dark cycle, $n=5$; under constant darkness, $n=1$ ). All data are aligned to clock time and averaged. $C$, MUA rhythmicity indices (top panel) were calculated using the following equations: before TSOI = (MUA peak1 - MUA trough1)/(MUA peak1 + MUA trough1); after TSOI = (MUA peak2 - MUA trough2)/(MUA peak2 + MUA trough2); where the SCN and frontal cortex MUA peaks were measured during the light and dark phases, respectively, and SCN MUA valleys were obtained from the dark phase (see Materials and Methods). P1, MUA peak1; T1, MUA trough1. The maximal fluctuation was scored as 1, and a lack of difference between the peak and trough was scored as 0 . Similarly, the diurnal rhythmicity of sleep is expressed as $\left(S W S_{D}-S W S_{1}\right) /\left(S W S_{L}+S W S_{D}\right)$, where SWS is the amount of SWS during the dark phase (D1), and SWS is the amount of SWS during the light phase (L1). D, Population analysis of diurnal rhythmicity for SWS time. SWS: $-0.23 \pm 0.04$ (before TSOl) versus $-0.06 \pm 0.04$ (after TSOI), 11 rats; $t=2.60, \mathrm{df}=10$, paired $t$ test, ${ }^{*} p=0.027$. E, Population analysis of diurnal rhythmicity for MUA in the SCN: $0.53 \pm 0.08$ (before TSOI) versus $0.62 \pm 0.07$ (after TSOI), 6 rats; $t=0.77, \mathrm{df}=10, t$ test, $p=0.46$.

(TL084, Texas Instruments) on the skull. Buffer amplifiers were connected to a counterbalanced commutator (MT GIKEN) via a flexible cable, and the rats were allowed to move freely in the recording chamber.

The neuronal activity of the SCN and other brain regions was amplified using a differential amplifier filtered (bandpass, 300-3000 Hz) and fed through a window discriminator (Nihon Kohden) that detected action potentials crossing a preset threshold. To detect the MUA diurnal amplitude and state dependence, we set the threshold of the window discriminator over a range of 20-50 spikes/s for practical purposes to keep the spike counts within the measurable range of the pulse counter. This threshold corresponded to 4 or 5 SDs of the MUA signals (ranging from 30 to $100 \mu \mathrm{V}$ ). Amplified signals and detected spikes were displayed on an oscilloscope, and the numbers of spikes per $50 \mathrm{~s}$ were counted by a pulse counter (MET1100; Nihon Kohden) and stored for further processing. This duration of sampling time was sufficient to evaluate the diurnal rhythmicity and sleep-wake state dependence. Occasionally, we used $1 \mathrm{~s}$ sampling to more closely examine the relationship between sleep/wake states and MUA. Usually three or four bipolar electrodes were implanted simultaneously, although the number of active electrodes that stably detected MUA rhythms over multiple days varied. Only recordings that were stable and showed minimal baseline drift over at least 1 week were included in the analysis. In total, MUA recordings from each rat experiment were obtained for 3 weeks or more.

Enzyme and drug administration (rat). Tryptophan side chain oxidase type I (TSOI; 20 units) was diluted in $3 \mathrm{ml}$ of saline and injected intraperitoneally under light diethyl ether anesthesia. Control subjects received saline alone. Para-chlorophenylalanine methyl ester hydrochloride (Wako) with Tween 20 in saline $(300 \mathrm{mg} / \mathrm{kg}$ ) or $\alpha$-methyltyrosine ( 150 or $250 \mathrm{mg} / \mathrm{kg}$; Wako) were also given intraperitoneally. For the TSOI experiment, the rats were deprived of food, but not water, to minimize tryptophan intake the night before and during the experiments. The total duration of food deprivation was restricted to within 3 days in the experiments. Although food deprivation ( $<3$ days) per se did not affect diurnal rhythmicity (Nakamaru-Ogiso et al., 2012), we continuously monitored each rat's condition and behavior using EEGs and an infrared camera and evaluated the body weight daily.

Locomotor activity (rat). The signal output of each rat movement sensor (Actomonitor, Medical Agent) or EMG was amplified, and the locomotor activity was quantified by counting the number of signal peaks crossing a preset threshold.

Data analysis (diurnal rhythmicity index) (rat/mouse). The diurnal rhythmicity index based on Michelson's contrast is versatile, able to 
A
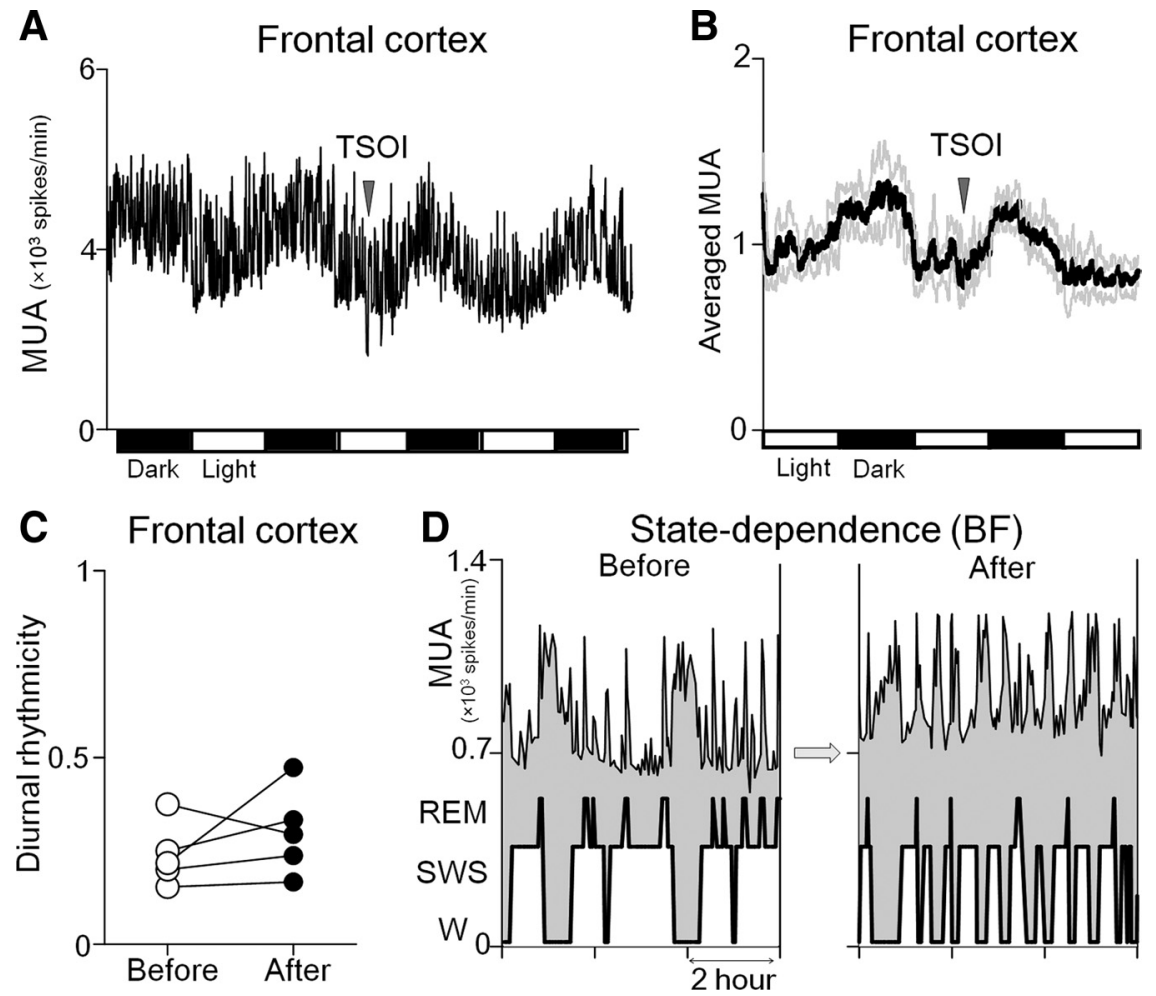

Figure 3. Night-dominant MUA rhythm in the cortex and state-dependence after 5 -HT depletion. $\boldsymbol{A}$, Frontal cortex MUAs also retain a strong diurnal rhythm after TSOl injection (arrowhead, left panel). Black/white bars, 12:12 h dark/light phase. $B$, Average of normalized MUA rhythms in the frontal cortex (mean $\pm S D, n=5$ ). C, Population analyses of diurnal MUA rhythmicity in the frontal cortex: $0.24 \pm 0.04$ (before TSOI) versus $0.30 \pm 0.05$ (after TSOl), 5 rats; $t=1.12$, df $=4$, paired $t$ test, $p=0.33$. $D$, The ultradian, state-dependent neuronal activity also remains unaffected by TSOl injection (6 $\mathrm{h}$ recording in BF).

internal cannula tip located $1 \mathrm{~mm}$ below the guide tube; Plastics One). During the injection, each mouse was lightly anesthetized with halothane. The tip of the cannula was positioned just above the basal forebrain region (AP, 0.8 $\mathrm{mm}$; LM, 0 mm; DV, $3.0 \mathrm{~mm}$ ). Screw EEG electrodes were implanted into the parietal cortex (AP, $-2 ; \mathrm{LM}, 1.5)$, and reference electrodes were placed in the cerebellum.

After at least 1 week of recovery from the implant surgery, continuous EEG and EMG recordings were initiated (telemetry system, Data Sciences International) and stored (Vital Recorder, Kissei Comtec). Sleep-wake states were scored automatically using computer software (SleepSign, Kissei Comtec). The criteria for sleep scoring (4-s epoch, 256-Hz sampling) were based on the amplitude and frequency of the EEG/ EMG recordings. The sleep criteria were set using baseline data (before drug application) from individual mice and applied to the experimental data (after drug treatment). After confirming the sleep-wake diurnal rhythm, we tested the effect of the drug on sleep-wake cycles.

Anatomical localization of the recording electrodes. At the end of the experiment, each animal (rat/mouse) was anesthetized with an overdose of sodium pentobarbiturate, and its brain was removed. Frozen or fixed (4\% paraformaldehyde) sections (40 $\mu \mathrm{m}$ thick) were subjected to Nissl staining to identify the recording site.

\section{Results}

Diurnal rhythmicity and state dependence of neuronal activity across brain regions

quantify rhythmicity during transient processes and indifferent to MUA absolute values, and it produces limited values ranging from -1 to 1 (Silver and Stryker, 1999). One represents the highest contrast, and 0 represents no contrast. The indices were calculated using MUA values from the day before and the day after TSOI injection (see Fig. 2C). First, we smoothed the MUAs using a linear moving average (for $30 \mathrm{~min}, 5 \mathrm{~min}$ steps). We then picked the highest MUA peak (P1) at midnight ( $6 \mathrm{~h}$ after lights off, between 1:00 A.M. and 3:00 A.M.) and the lowest at midday (6 $\mathrm{h}$ after lights on, between 1:00 P.M. and 3:00 P.M.). The diurnal index before TSOI was taken as $(\mathrm{P} 1-\mathrm{T} 1) /(\mathrm{P} 1+\mathrm{T} 1)$. Similarly, the MUA peaks (P2) at midnight and the MUA troughs (T2) after TSOI administration were used to create diurnal indices after TSOI $[(\mathrm{P} 2-\mathrm{T} 2) /(\mathrm{P} 2+$ T2)]. In the case of the SCN MUA, the peaks were sampled at midday.

The amount of SWS or REM sleep during the dark phase (i.e., D1) and the light phase (L1) (12 h each) was similarly used to calculate rhythmicity indices $[(\mathrm{D} 1-\mathrm{L} 1) /(\mathrm{D} 1+\mathrm{L} 1)]$ before and after TSOI (or drug) application. We analyzed single days before and after the TSOI injection. We also calculated the average MUAs of the SCN, cortex, and BF/POA. Because the absolute values of the MUAs varied substantially, even within the same brain region, the individual MUAs at each time point were normalized by the total number of neuronal spikes before or after the TSOI injection (2.5 days), and the MUAs were then averaged. These averaged MUAs were amenable to the statistics of the rhythmicity index.

Drug microinjection into the basal forebrain (mouse). To test whether the observed effects of 5-HT depletion induced by TSOI or p-chlorophenylalanine (PCPA) were due to secondary melatonin depletion, we also used C57BL/6 mice, which lack the key enzyme for melatonin synthesis from 5 -HT. Like rats, mice show clear diurnal sleep wake patterns. Male mice ( 8 weeks, $30 \mathrm{~g}$ at time of surgery; Japan SLC) were microinjected with ritanserin. Ritanserin (12.5 $\mu \mathrm{g}$; Wako) was dissolved in $0.5 \mu \mathrm{l}$ of vehicle solution (10\% DMSO in saline) by sonication before use and slowly injected with a micro-syringe via a polyethylene tube connected to an injection cannula (guide cannula 6 or $7 \mathrm{~mm}$ in length,
In the BF/POA, the MUA increased during waking states (W) or rapid eye movement (REM) sleep and decreased during slowwave sleep (SWS) (Fig. 1A). Comparable to these findings in the $\mathrm{BF} / \mathrm{POA}$, prominent MUA changes were associated with sleepwake states in most rat brain regions observed, including thalamus and brainstem (Fig. $1 A, B$ ), which participate directly in sleep-wake control as part of the reticular activating system. State-dependence of MUA varied from region to region. But the MUA associated with W or REM was usually more prominent in thalamus and much less significant in the SCN (Deboer et al., 2003) (Fig. $1 B$ ). In addition, the MUA in various other brain regions (basal ganglia, limbic system) also exhibited diurnal rhythms (Fig. 1B). Daytime-dominant circadian neuronal activity is a hallmark of the SCN in nocturnal and diurnal rodents (Inouye and Kawamura, 1979; Deboer et al., 2003). In contrast, night-dominant MUA rhythms are prevalent in brain regions outside the SCN (Inouye and Kawamura, 1979; Nakamura et al., 2008) (Fig. 1B). We observed variability of state dependence in degree or directionality (i.e., W active, SWS active; Fig. $4 A$ ) and diurnal activity in amplitude/waveform, despite a clear diurnal MUA in each region (e.g., SCN, cortex, BF/POA) (see Figs. $2 B, 3 B, 5 B$ ).

\section{Decoupling of sleep-wake cycles from SCN circadian activity during 5-HT depletion}

To further explore the integration of circadian and ultradian MUA rhythms, we acutely perturbed the diurnal rhythm of rat sleep-wake cycles via systemic 5-HT depletion. Brain 5-HT was transiently reduced by depleting tryptophan in the blood (Nakamaru-Ogiso et al., 2012). Since tryptophan is a precursor of 
brain 5-HT, to minimize the uncontrolled intake of tryptophan from the diet, rats were deprived of food during these experiments. Briefly ( $<3$ days), food-deprived control rats show a robust sleep-wake diurnal rhythm (Nakamaru-Ogiso et al., 2012). Intraperitoneal injection of the tryptophan-degrading enzyme TSOI then resulted in a $70-90 \%$ depletion of brain 5-HT (Nakamaru-Ogiso et al., 2012). Subsequently, locomotor activity was diminished, sleep patterns were fragmented, and the daily rhythm of sleep-wake cycles was lost for $\sim 36 \mathrm{~h}$ in TSOI-treated rats under normal light-dark cycles (Fig. 2A). These results are consistent with a previous report showing that chronic tryptophan depletion lowered the levels and circadian amplitudes of wheel-running activity (Kawai et al., 1994).

Because SCN neurons express several 5-HT receptor subtypes and receive dense 5-HT innervation, we determined whether 5-HT depletion altered SCN oscillatory function (Herzog et al., 1998; de la Iglesia et al., 2000; Nakamura et al., 2002; Ohta et al., 2005). As expected (reviewed by Morin and Allen, 2006), the circadian MUA rhythm of the SCN remained intact, even when the rat was maintained in constant darkness (Fig. $2 A)$. The normalized SCN MUAs from all rats $(n=6)$ were averaged, revealing ro-

bust oscillations in the SCN (Fig. $2 B$ ) after 5-HT depletion. All SCN experiments, except for Figure $2 A$, were performed under light:dark condition throughout the experiments. To quantify the degree of diurnal MUA rhythmicity and sleep, we calculated a diurnal rhythmicity index (Fig. 2C) in which a value of 1 represents the highest contrast between MUA peak and trough activity, and a value of 0 represents no difference. Statistical analyses confirmed that the diurnal SWS rhythm in particular was lost following 5-HT depletion (Fig. 2D), whereas the diurnal MUA rhythm in the SCN was unchanged (Fig. 2E). These findings demonstrated that sleep-wake regulation is uncoupled from SCN rhythmicity after 5-HT depletion.

MUA in the frontal cortex maintained night-dominant rhythms after 5-HT depletion (Fig. 3A-C), while the diurnal rhythm of sleep based on EEGs from frontal cortex was lost after 5-HT depletion (Fig. 2D) (Nakamaru-Ogiso et al., 2012). The state-dependent neuronal activity and the magnitude of that activity remained unchanged in the BF (Fig. 3D). In addition, the diurnal MUA in other brain regions, such as the striatum, was unaffected by TSOI treatment. We observed wake-active patterns in most MUA recordings. However, a few sleep-active recordings were also obtained. Both wake-active and sleep-active MUAs showed dark-dominant diurnal activities (Fig. 4A). MUA patterns thus appear to consist of separable circadian and state-dependent components (Fig. $4 B$ ), in line with previous findings in the SCN (Deboer et al., 2003) (Fig. 4B).

\section{Selective reduction of diurnal MUA in the $\mathrm{BF} / \mathrm{POA}$ region during 5-HT depletion}

To determine the specific brain regions responsible for the loss of diurnal sleep rhythm, we focused on MUA patterns in the BF/

\section{Preoptic area (simultaneously recorded)}

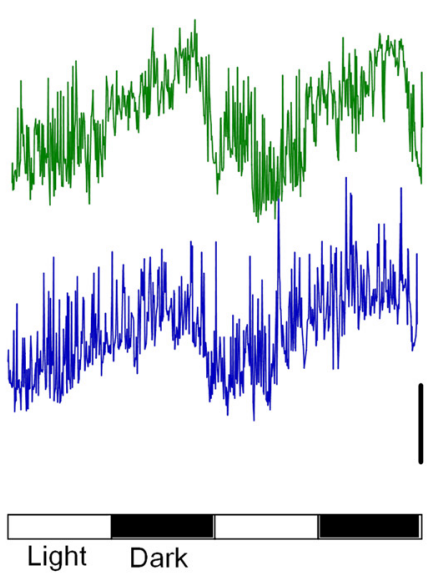

State-dependent
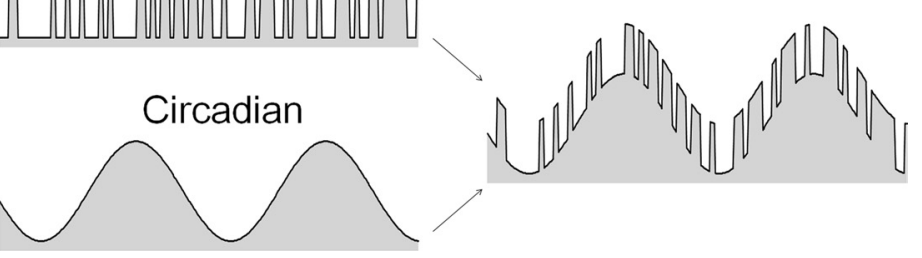
dependence. Representative MUAs were simultaneously recorded from the preoptic area of the same rat. One MUA showed the W/REM active pattern (green line, left panel), another MUA displayed the SWS/REM active pattern (blue line, left panel), and both MUAs showed diurnal rhythmicity (right panel). The green curve was arbitrarily shifted upward for visual comparison (scale bar, $10^{3}$ spikes/min). $\boldsymbol{B}$, Schematic representation of neuronal activity comprised of both circadian and state-dependent components.

POA. We found that the MUA rhythms in the BF/POA were severely disrupted following TSOI injection (Fig. $5 A, B$ ). The response to 5-HT depletion was complex: the BF/POA MUA failed to increase during the dark phase in many cases (e.g., Fig. 5A,E), whereas other MUAs showed unusual increases during the light phase and complementary decreases during the dark phase. The reduction of diurnal rhythmicity in the $\mathrm{BF} / \mathrm{POA}$ was significant (Fig. $5 \mathrm{C}$ ), and the reduction of MUA rhythmicity coincided with sleep fragmentation and decreased locomotor activity. Both wake-active and sleep-active MUAs reduced dark-dominant diurnal rhythmicity after TSOI. Therefore, we treated them together for the calculation of the diurnal rhythmicity index. The MUA rhythmicity gradually recovered after $48 \mathrm{~h}$ as brain 5-HT levels returned to normal (Nakamaru-Ogiso et al., 2012).

We further tested the effects of a 5-HT synthesis inhibitor PCPA (300 mg/kg i.p.), which also causes extensive 5-HT depletion in the brain. Consistent with observations following 5-HT depletion with TSOI, both the diurnal MUA rhythmicity in the $\mathrm{BF} / \mathrm{POA}$ and diurnal sleep-wake cycles were disrupted following PCPA administration $[0.217 \pm 0.028$ (rhythm index before PCPA) vs $0.063 \pm 0.055$ (rhythm index after PCPA), mean \pm SEM, $t$ value $=3.46, \mathrm{df}=5$, paired $t$ test, $p=0.0181,6$ recording sites, 3 rats] (Fig. $5 D$ ). These data underscore the importance of the 5-HT system for diurnal MUA rhythmicity in the BF/POA and in global diurnal sleep-wake cycles. As a control for other monoamine neurotransmitters, we depleted catecholamines using a supramaximal dose of $\alpha$-methyl-p-tyrosine, which inhibits tyrosine hydroxylase, and we observed no subsequent change in the MUA patterns of the BF/POA (Fig. 5E). 


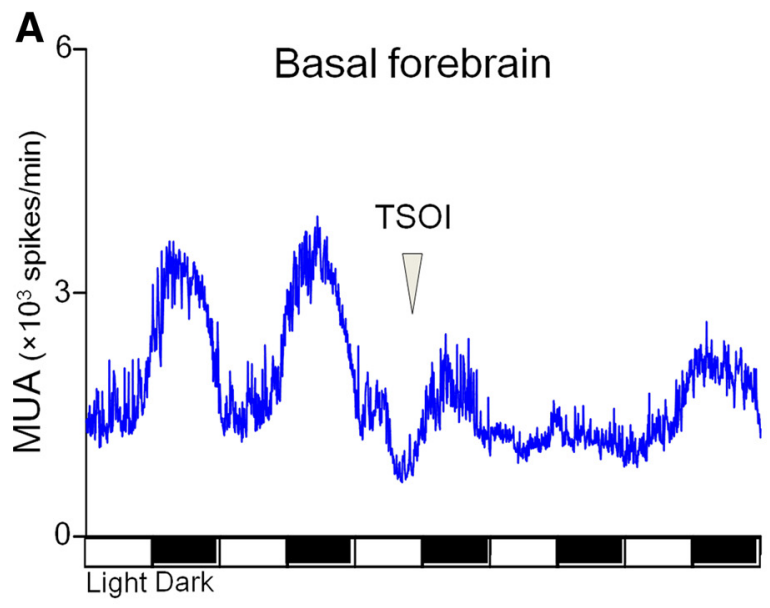

D

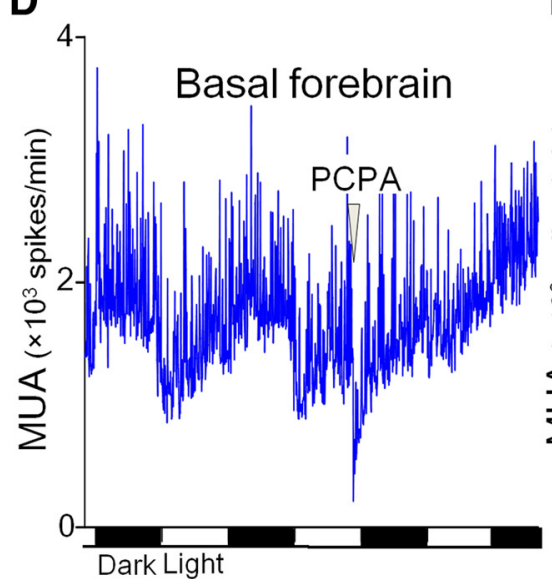

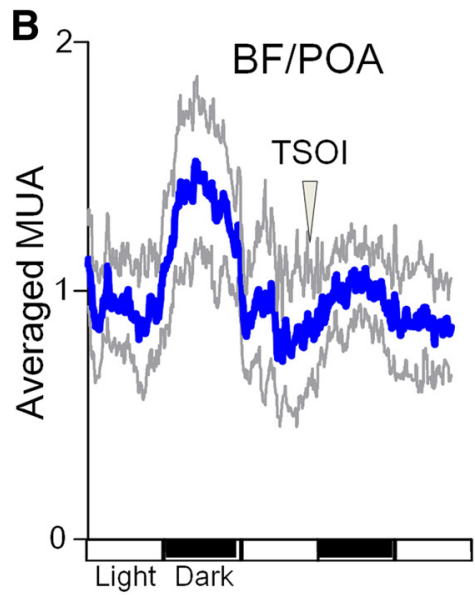

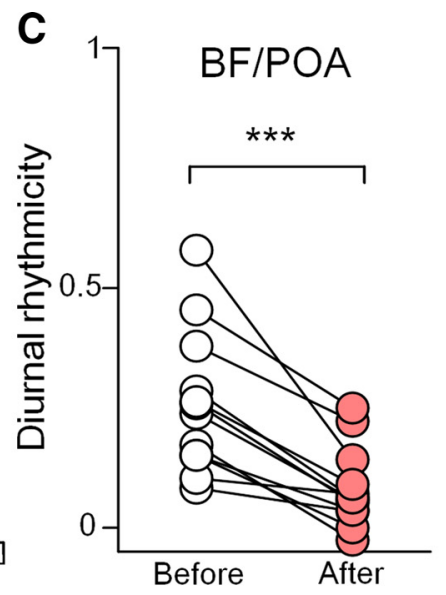

$\mathbf{F}$
E

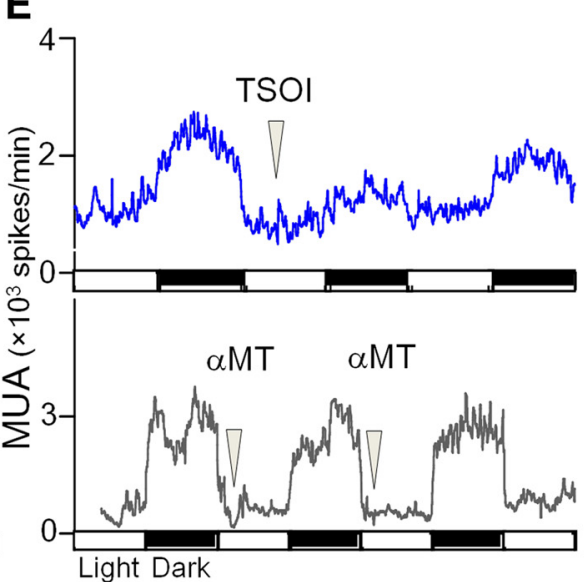

F TSOI Frontal cortex

Figure 5. Collapsed MUA rhythms in the BF/POA upon 5-HT depletion. A, Typical loss of diurnal MUA rhythm in the BF region (medial septum/diagonal band) upon 5-HT depletion (arrowhead, TSOI, 20 unit i.p.). Black/white bars, 12:12 h dark/light phase. $B$, Average MUA rhythms in the BF/POA (mean \pm SD, 12 recording sites, 8 rats). $\boldsymbol{C}$, Population diurnal rhythmicity index from the BF/P0A: $0.26 \pm 0.04$ (before TSOI) versus $0.08 \pm 0.02$ (after TSOI); 12 recording sites, 8 rats, $t=6.03, \mathrm{df}=11$, paired $t$ test, ${ }^{* * *} p<0.001 . D$, Diurnal MUA rhythmicity in the BF/P0A is reduced following systemic administration of the serotonin synthesis inhibitor PCPA ( $300 \mathrm{mg} / \mathrm{kg}$ i.p.). $E$, Diurnal MUA in the BF region (substantia innominata) is reduced upon 5 -HT depletion (top, TSOI), but not after catecholamine depletion [bottom, $\alpha$-methyl-tyrosine (a-MT); first injection, $150 \mathrm{mg} / \mathrm{kg}$; second injection, $250 \mathrm{mg} / \mathrm{kg}$ ]. Data were taken from the same recording site of the same rat. $\boldsymbol{F}$, Simultaneous recordings of MUA in frontal cortex and medial septum/diagonal band (MSDB) from the same rat (scale bar, 500 spikes/min). The MSDB reduced its MUA rhythmicity while it was preserved in the cortex, suggesting regional specificity of 5-HT depletion.

The changes in MUA rhythms in the BF/POA were striking and reproducible. Simultaneous recordings from the frontal cortex and basal forebrain (medial septum/diagonal band) (Fig. 5F) confirmed the regional selectivity of changes in the MUA following brain 5-HT depletion. In contrast, diurnal brain temperature rhythm did not change in the $\mathrm{BF} / \mathrm{POA}$ following TSOI injection (Nakamaru-Ogiso et al., 2012), which suggests that thermoregulation and metabolic activity are preserved in the brain.

The subparaventricular zone (SPZ) is a major output from the SCN (Deurveilher and Semba, 2005; Saper et al., 2005). We also observed night-dominant, baseline MUA rhythms in the SPZ (Fig. 6) (Nakamura et al., 2008). Similar to the BF/POA, these SPZ MUA rhythms were significantly abolished upon acute 5-HT depletion $[0.364 \pm 0.040$ (rhythm index before TSOI) vs $0.253 \pm$ 0.057 (rhythm index after TSOI), $t=2.81, \mathrm{df}=13$, paired $t$ test, $p=0.0146,14$ recording sites, 6 rats)]. However, a substantial number of SPZ MUAs also persisted after 5-HT depletion (Fig. $6 A, B$; MUAs with a rhythmicity index ratio after TSOI vs before TSOI, $>0.6,6$ recording sites, $t=0.33, \mathrm{df}=6$, paired $t$ test, $p=$ $0.756)$. Simultaneously recorded MUAs from the same rat revealed a differential SPZ response to 5-HT depletion (Fig. $6 A, C$ ), suggesting a coexistence of these two response types in the SPZ.

\section{Local blockade of 5-HT signaling in the BF/POA disrupts} diurnal SWS rhythm

Because the diurnal MUA rhythm in the BF/POA was specifically disrupted after 5-HT depletion in the brain, we hypothesized that the 5-HT signals in this region play a critical role in the regulation of diurnal sleep-wake rhythms. In addition, since melatonin is synthesized from 5-HT, we wondered whether the effects on sleep/wake cycles attributed to 5-HT depletion (by TSOI or PCPA) were actually secondary to "melatonin depletion." To preclude this possibility, here we used the C57BL/6 mouse strain, in which a critical enzyme for melatonin precursor synthesis (arylalkylamine $N$-acetyltransferase) is missing, thus eliminating any melatonin effects (Kasahara et al., 2010). We investigated the effects of the local blockade of 5-HT neurotransmission by microinjection of the $5-\mathrm{HT}_{2}$ receptor antagonist ritanserin (Kantor et al., 2002) into the BF/POA of mice (Fig. 7).

Before the onset of the dark phase, when mice become more active and 5-HT release is higher, a small amount of ritanserin $(12.5 \mu \mathrm{g} / 10 \%$ DMSO in saline, $<0.5 \mu \mathrm{l})$ was delivered into the medial septum/diagonal band of Broca (a basal forebrain region) via chronically implanted injection cannulae. On the first night after ritanserin administration, locomotor activity was decreased and the diurnal SWS rhythmicity was significantly reduced, 
whereas REM sleep rhythmicity remained unaltered (Fig. $7 A, B$ ). The SWS diurnal rhythmicity of rats tended to be higher than that of mice, but this difference did not reach statistical significance $(t$ test, $t=$ 1.49 , df $=14, p=0.159)$. Similarly, the magnitude of change following ritanserin in mice was not significantly different from that following TSOI in rats (before - after TSOI, $0.172 \pm 0.066$; vehicle - ritanserin, $0.071 \pm 0.016$; $t$ test, $t=$ $1.00, \mathrm{df}=14, p=0.334$ ). Taken together, these results confirm in mice, as in rats, a crucial role for 5-HT signaling in the BF for diurnal rhythmicity.

\section{Discussion}

Our data show that acute 5-HT depletion leads to a loss of diurnal sleep-wake cycles and a decrease of diurnal MUA rhythms in the BF/POA, whereas the SCN MUA activity is preserved. Local blockade of 5-HT neurotransmission in the BF/POA is sufficient to disturb diurnal sleep-wake cycles. Therefore, the diurnal MUA rhythm in the BF/POA is integral to coupling SCN circadian signals to ultradian sleep-wake cycles under serotonergic control (Fig. 7C).

Sleep-active and wake-active neurons are reported to coexist in the $\mathrm{BF} / \mathrm{POA}$ (Takahashi et al., 2009). We also observed primarily wake-active patterns and some sleep-active MUA recordings, consistent with a bias toward wake-active units in the basal forebrain (Hassani et al., 2009). This state dependence was not affected by 5 -HT depletion (Fig. 3D), much like an earlier report demonstrating robust state-related neuronal activity in the thalamus (lateral geniculate nucleus) following local 5-HT depletion (Marks et al., 1989). It has been repeatedly demonstrated that circadian behavior is not dependent on 5-HT input by destruction of 5-HT neurons using electrical lesion (Block and Zucker, 1976) or neurotoxin (5,7-dihydroxytryptamine) (Smale et al., 1990; Morin and Blanchard, 1991). Furthermore, continuous SCN MUA rhythm after 5-HT reduction is expected, given the fact that SCN brain slices devoid of 5-HT innervation maintain circadian neuronal firing (Barnes et al., 2003; Ikeda et al., 2003; Yamaguchi et al., 2003; Tischkau et al., 2004; Hamada and Shibata, 2010). However, it was largely unknown whether SCN activity in vivo is maintained or disrupted in rats that have lost diurnal sleep/wake rhythm after 5-HT depletion, because behavioral arrhythmicity can result from desynchronization of individual SCN clock neurons (Ohta et al., 2005). In this respect, our finding that SCN activity was maintained after 5 -HT depletion by TSOI in rats (Fig. 2) is significant and consistent with previous reports (Block and Zucker, 1976; Smale et al., 1990; Morin and Blanchard, 1991). Our data also indicate that other brain regions (i.e., BF/POA) outside the SCN mediate diurnal rhythms of sleep-wake and locomotor activity. However, our findings do not rule out the possibility that the function of specific subregions in the SCN (LeSauter and Silver, 1999) or diffusible factors mediating circadian signals could be impaired by 5-HT depletion (Silver et al., 1996; Kramer et al., 2001; Cheng et al., 2002).
In contrast to the $\mathrm{SCN}$, night-dominant MUAs in the $\mathrm{BF} /$ POA reduced their rhythmicity (Fig. 5). This type of inverted diurnal pattern may potentially arise from excessive waking (enhanced MUA) during the night in rats, but this explanation seems unlikely. If the MUA consisted only of a state-dependent component, the diurnal patterns would be rectangular, similar to those found in the thalamus (Fig. $1 B$ ) where the diurnal MUA amplitudes are not correlated with the degree of state dependence. Moreover, night-dominant MUA rhythms were occasionally found in some brain regions, demonstrating the opposite state dependence (enhanced activity during sleep) (Fig. 4A). Thus, we hypothesize that the MUA patterns consist of separable circadian and state-dependent components (Fig. $4 B$ ), although it is unknown whether single neurons simultaneously encode both the circadian rhythm and state dependence or whether these two phenomena exist independently (Ono et al., 1987; Welsh et al., 2010). Since entrainment by a light:dark cycle may resist change of circadian sleep/wake rhythmicity after 5-HT depletion, a more stringent test under constant dark condition is required in the future to reveal roles of the 5-HT system in circadian regulation of MUA, sleep/ wake cycles, locomotor activity, and photic influence (Morin and Allen, 2006).

Local ritanserin controls for the possible side effects of systemic TSOI-induced 5-HT depletion, as tryptophan depletion may also inhibit general protein synthesis and/or melatonin synthesis (Nakamaru-Ogiso et al., 2012). Notably, in the pineal body serotonin is transformed into melatonin, which also influences sleep and circadian rhythms. The C57BL/6 mice used in this 
A
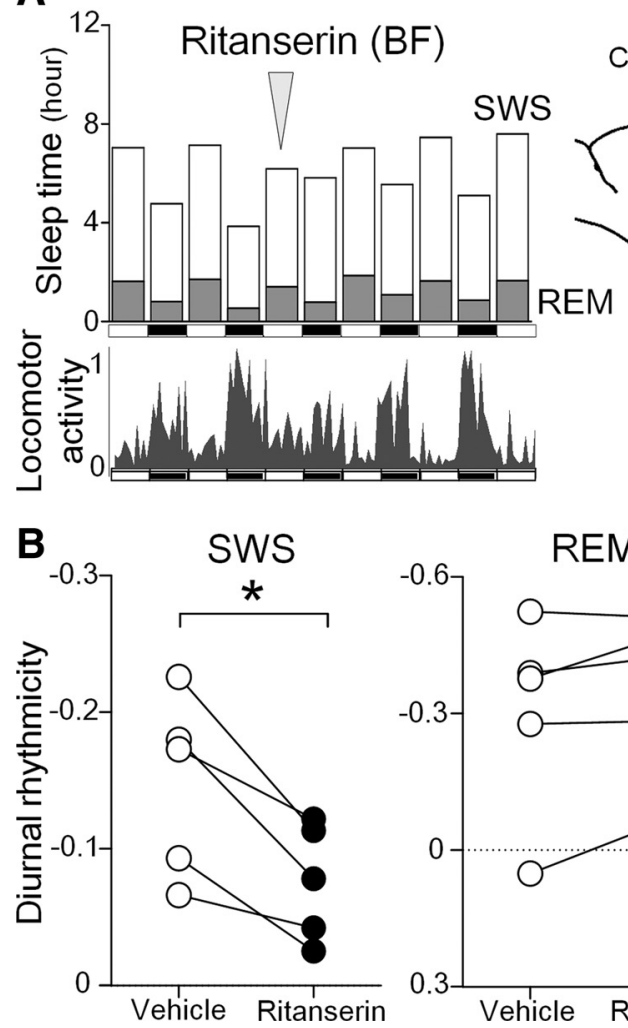

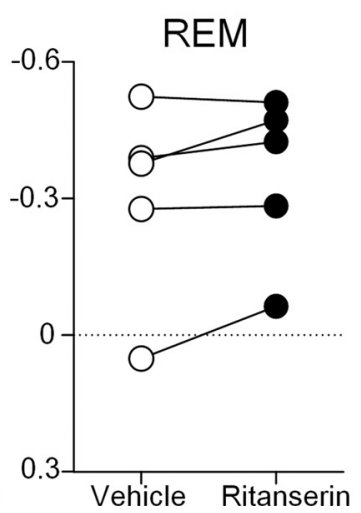

C
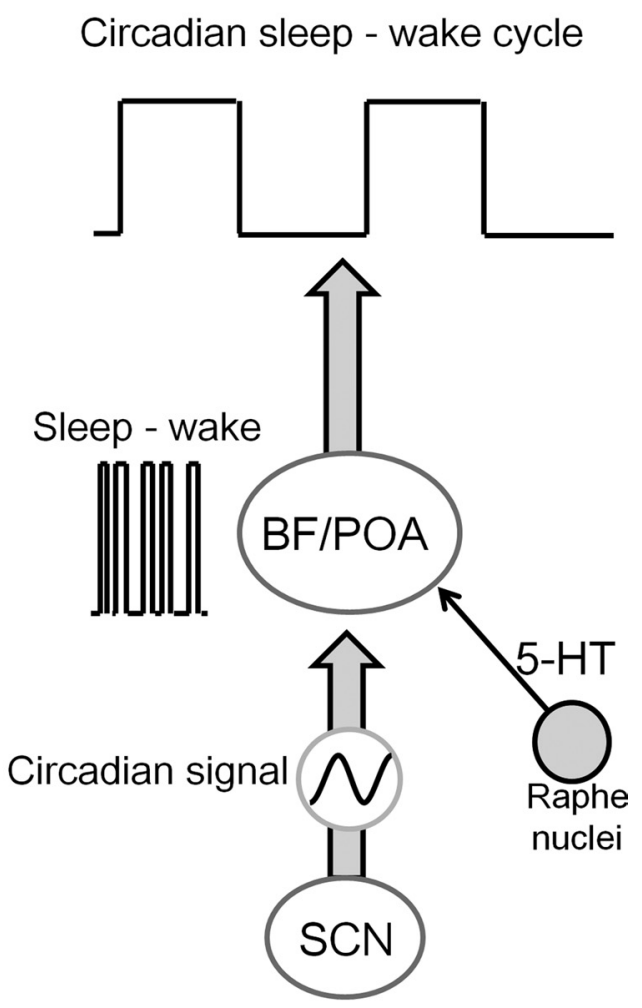

Figure 7. Focal 5- $\mathrm{HT}_{2}$ receptor blockade in the BF disrupts diurnal SWS rhythm. $\boldsymbol{A}$, Reduction of diurnal SWS rhythm and decreased locomotor activity upon microinjection of the serotonin antagonist ritanserin (arrowhead) into the BF region (inset). Note that REM sleep rhythmicity remains intact. $\boldsymbol{B}$, Population analyses of diurnal rhythmicity for SWS and REM. SWS: $-0.15 \pm 0.03$ (vehicle) versus $-0.08 \pm 0.02$ (ritanserin); paired $t$ test, $t=4.40, \mathrm{df}=4, p=0.0117 ; \mathrm{REM}:-0.30 \pm 0.10$ (vehicle) versus $-0.35 \pm 0.08$ (ritanserin); $t=1.94, \mathrm{df}=4$, paired $t$ test, $p=0.1250$. Data were obtained from the same mice $(n=5)$. C, Schematic model. The SCN sends circadian clock signals to various brain regions including the BF/POA (and the raphe nucleus), which is a center of sleep-wake regulation. Under 5-HT control, the BF/POA integrates the circadian signal from the SCN with ultradian sleep-wake cycles to express the diurnal sleep-wake rhythm.

study lack a critical enzyme for melatonin synthesis (Kasahara et al., 2010). Therefore, the involvement of the melatonin system is precluded in this study. However, a comparison of C57BL/6 with $\mathrm{C} 3 \mathrm{H}$ mice, which carry the intact enzymatic pathway, would be interesting to further determine a potential interaction between serotonin and melatonin systems in the circadian regulation of sleep-wake cycles.

Our data further indicate that the 5-HT input to the BF/POA via the excitatory action of $5-\mathrm{HT}_{2}$ receptors (Landolt and Wehrle, 2009) plays a critical role in the diurnal regulation of SWS and night-dominant locomotor activity. We cannot preclude the possibility that the effect of 5-HT blockade is mediated by regions outside the BF/POA, because we used a relatively large volume for microinjection experiments (Fig. 7A, $B$ ), and the drug could have spread to other hot spots beyond the BF/POA. However, we think that the effect of ritanserin can still be attributed to the $\mathrm{BF} / \mathrm{POA}$ for several reasons. First, 5-HT2A/2C receptors are abundant in this region (Cornea-Hébert et al., 1999; Clemett et al., 2000). Second, our findings are consistent with previous reports that sleep-wake diurnal oscillations are reduced after selective cholinergic basal forebrain lesion (Kapás et al., 1996). Third, while SWS diurnal rhythmicity was reduced by the ritanserin injection, REM sleep diurnal rhythmicity, which is regulated by adjacent brain regions (Lu et al., 2002), was well preserved in the same mice. Our ritanserin experiment also suggests that the diurnal rhythmicity of REM sleep may be regulated by a different 5-HT receptor subtype or other brain regions. Collectively, our findings directly establish a connection between MUA rhythm in the BF/POA and diurnal sleep-wake rhythm. Future studies involving conditional gene deletions (Mieda and Sakurai, 2011) in the mouse BF will be of great interest in this regard.

Most SCN neurons densely innervate the SPZ and travel further into the dorsomedial hypothalamus (DMH) (Deurveilher and Semba, 2005). Lesions of the ventral SPZ or DMH cause a disruption of the circadian sleep-wake rhythm and reduction of locomotor activity in rats, whereas brain temperature rhythm is not affected (Aston-Jones et al., 2001; Lu et al., 2001; Chou et al., 2003). Interestingly, the 5-HT-depleted rats in this study also maintained their diurnal brain-temperature rhythm (Nakamaru-Ogiso et al., 2012) while exhibiting a loss of diurnal sleep-wake rhythms and reduced locomotor activity. We thus hypothesize that the circadian signal from the SCN reaches the $\mathrm{BF} / \mathrm{POA}$ via the ventral $\mathrm{SPZ}$ and $\mathrm{DMH}$ to regulate circadian sleep-wake cycles.

Indeed, we observed that MUA rhythms in the SPZ collapsed following 5-HT depletion, which suggests that the BF/POA may function in concert with the SPZ and DMH. As we found that MUAs in the SPZ differentially respond to 5-HT depletion (Fig. 6), individual/subregional SPZ cells may mediate SCN circadian signals separately (Lu et al., 2001). This may explain the persistence of the MUA (e.g., in the cortex) and brain temperature rhythms after 5-HT depletion despite a reduction of MUA rhythms in the BF/POA. It is also possible that selected synaptic connections in the SCN/SPZ or BF/POA are compromised by the acute drop in 5-HT. To confirm this, detailed mapping studies are needed to elucidate the temporal relationship between MUAs 
of the SPZ, sleep/wake cycles, locomotor activity, and the response to 5-HT manipulation.

Based on our current results, we propose a straightforward model: circadian signals from the SCN are integrated with ultradian sleep-wake cycles generated in the BF/POA, and the 5-HT system may control the excitability of $\mathrm{BF} / \mathrm{POA}$ neurons in a statedependent manner (Fig. 7C). Alternatively, because SCN output to the raphe nuclei is relayed via the DMH (Deurveilher and Semba, 2008), and circadian rhythms of 5-HT release in the brain have been reported (Portas and McCarley, 1994; Dudley et al., 1998; Grossman et al., 2000), the SCN may also function through the raphe to regulate rhythms in other brain regions, including the BF/POA (Zant et al., 2011). Furthermore, 5-HT release is enhanced by motor activity (Gerin et al., 2008), and 5-HT has been suggested to mediate nonphotic phase shifting (Mistlberger et al., 1998; Glass et al., 2003). Thus, it is reasonable to suppose that feedback from rhythmic locomotor activity may also affect $\mathrm{BF} / \mathrm{POA}$ and SPZ MUAs.

Because 5-HT receptor subtypes exert excitatory (5-HT2) or inhibitory (5-HT1) action on postsynaptic neurons, 5-HT may directly regulate cell excitability in the $\mathrm{BF} / \mathrm{POA}$ and $\mathrm{SPZ}$. These regions, in turn, may affect circadian sleep-wake patterns. However, it is unclear whether 5-HT is only "permissive" for the expression of rhythmicity driven by the SCN or if the 5-HT system plays a more active "instructive" role. Future studies should therefore explore the relationships among individual cellular responses in the $\mathrm{BF} / \mathrm{POA}$, sleep-wake behavior and manipulation of 5-HT neurotransmission.

Basal forebrain regions have been implicated in sleep fragmentation and the homeostatic regulation of sleep (Kalinchuk et al., 2008; Matsuki et al., 2009). Therefore, a reduction in MUA may be linked to a failure to consolidate the sleep pattern. We speculate that the circadian oscillation of neuronal excitability in the $\mathrm{BF} / \mathrm{POA}$, which defines the sleep or wake state, is controlled by input signals from the SCN (Fig. 7C). Because 5-HT neurons are most active during the wake state (Jacobs et al., 2002), the excitatory influence of 5- $\mathrm{HT}_{2}$ receptors should enhance the MUA in a positive feedback manner to consolidate the sleep-wake rhythm. Circadian neuronal activity across various brain regions may underlie other brain functions (Ruby et al., 2008; Phan et al., 2011) and disorders. This influence may be mediated through interactions with the brain 5-HT system, which is necessary for brain plasticity (Jitsuki et al., 2011) and has been implicated in psychiatric disorders (Takahashi et al., 2008; Wulff et al., 2010) such as depression and insomnia.

\section{References}

Aston-Jones G, Chen S, Zhu Y, Oshinsky ML (2001) A neural circuit for circadian regulation of arousal. Nat Neurosci 4:732-738. CrossRef Medline

Barnes JW, Tischkau SA, Barnes JA, Mitchell JW, Burgoon PW, Hickok JR, Gillette MU (2003) Requirement of mammalian Timeless for circadian rhythmicity. Science 302:439-442. CrossRef Medline

Block M, Zucker I (1976) Circadian rhythms of rat locomotor activity after lesions of the midbrain raphe nuclei. J Comp Neurol 109:235-247. CrossRef

Cheng MY, Bullock CM, Li C, Lee AG, Bermak JC, Belluzzi J, Weaver DR, Leslie FM, Zhou QY (2002) Prokineticin 2 transmits the behavioural circadian rhythm of the suprachiasmatic nucleus. Nature 417:405-410. CrossRef Medline

Chou TC, Scammell TE, Gooley JJ, Gaus SE, Saper CB, Lu J (2003) Critical role of dorsomedial hypothalamic nucleus in a wide range of behavioral circadian rhythms. J Neurosci 23:10691-10702. Medline

Clemett DA, Punhani T, Duxon MS, Blackburn TP, Fone KC (2000) Immunohistochemical localisation of the 5-HT2C receptor protein in the rat CNS. Neuropharmacology 39:123-132. CrossRef Medline
Colwell CS (2011) Linking neural activity and molecular oscillations in the SCN. Nat Rev Neurosci 12:553-569. CrossRef Medline

Cornea-Hébert V, Riad M, Wu C, Singh SK, Descarries L (1999) Cellular and subcellular distribution of the serotonin 5-HT2A receptor in the central nervous system of adult rat. J Comp Neurol 409:187-209. CrossRef Medline

de la Iglesia HO, Meyer J, Carpino A Jr, Schwartz WJ (2000) Antiphase oscillation of the left and right suprachiasmatic nuclei. Science 290: 799-801. CrossRef Medline

Deboer T, Vansteensel MJ, Détári L, Meijer JH (2003) Sleep states alter activity of suprachiasmatic nucleus neurons. Nat Neurosci 6:1086-1090. CrossRef Medline

Deurveilher S, Semba K (2005) Indirect projections from the suprachiasmatic nucleus to major arousal-promoting cell groups in rat: implications for the circadian control of behavioural state. Neuroscience 130:165-183. CrossRef Medline

Deurveilher S, Semba K (2008) Reciprocal connections between the suprachiasmaitc nucleus and the midbrain raphe nuclei: Aputative role in the circadian control of behavioral states: In: Serotonin and sleep: molecular, functional and clinical aspects (Monti JM, Pandi-Perumal SR, Jacobs BL, Nutt DJ eds), pp 103-131. Basel: Birkhäuser.

Dudley TE, DiNardo LA, Glass JD (1998) Endogenous regulation of serotonin release in the hamster suprachiasmatic nucleus. J Neurosci 18: 5045-5052. Medline

Frank MG, Stryker MP, Tecott LH (2002) Sleep and sleep homeostasis in mice lacking the 5-HT2c receptor. Neuropsychopharmacology 27:869873. CrossRef Medline

Gerin C, Teilhac JR, Smith K, Privat A (2008) Motor activity induces release of serotonin in the dorsal horn of the rat lumbar spinal cord. Neurosci Lett 436:91-95. CrossRef Medline

Glass JD, Grossman GH, Farnbauch L, DiNardo L (2003) Midbrain raphe modulation of nonphotic circadian clock resetting and 5-HT release in the mammalian suprachiasmatic nucleus. J Neurosci 23:7451-7460. Medline

Grossman GH, Mistlberger RE, Antle MC, Ehlen JC, Glass JD (2000) Sleep deprivation stimulates serotonin release in the suprachiasmatic nucleus. Neuroreport 11:1929-1932. CrossRef Medline

Hamada T, Shibata S (2010) The role of GABAergic neuron on NMDA- and SP-induced phase delays in the suprachiasmatic nucleus neuronal activity rhythm in vitro. Neurosci Lett 468:344-347. CrossRef Medline

Hassani OK, Lee MG, Henny P, Jones BE (2009) Discharge profiles of identified GABAergic in comparison to cholinergic and putative glutamatergic basal forebrain neurons across the sleep-wake cycle. J Neurosci 29: 11828-11840. CrossRef Medline

Herzog ED, Takahashi JS, Block GD (1998) Clock controls circadian period in isolated suprachiasmatic nucleus neurons. Nat Neurosci 1:708-713. CrossRef Medline

Huang ZL, Urade Y, Hayaishi O (2007) Prostaglandins and adenosine in the regulation of sleep and wakefulness. Curr Opin Pharmacol 7:33-38. CrossRef Medline

Ikeda M, Sugiyama T, Wallace CS, Gompf HS, Yoshioka T, Miyawaki A, Allen CN (2003) Circadian dynamics of cytosolic and nuclear $\mathrm{Ca}^{2+}$ in single suprachiasmatic nucleus neurons. Neuron 38:253-263. CrossRef Medline

Inouye ST, Kawamura H (1979) Persistence of circadian rhythmicity in a mammalian hypothalamic "island" containing the suprachiasmatic nucleus. Proc Natl Acad Sci U S A 76:5962-5966. CrossRef Medline

Jacobs BL, Martín-Cora FJ, Fornal CA (2002) Activity of medullary serotonergic neurons in freely moving animals. Brain Res Brain Res Rev 40:45-52. CrossRef Medline

Jitsuki S, Takemoto K, Kawasaki T, Tada H, Takahashi A, Becamel C, Sano A, Yuzaki M, Zukin RS, Ziff EB, Kessels HW, Takahashi T (2011) Serotonin mediates cross-modal reorganization of cortical circuits. Neuron 69:780-792. CrossRef Medline

Jones BE (2005) From waking to sleeping: neuronal and chemical substrates. Trends Pharmacol Sci 26:578-586. CrossRef Medline

Kalinchuk AV, McCarley RW, Stenberg D, Porkka-Heiskanen T, Basheer R (2008) The role of cholinergic basal forebrain neurons in adenosinemediated homeostatic control of sleep: lessons from 192 IgG-saporin lesions. Neuroscience 157:238-253. CrossRef Medline

Kantor S, Jakus R, Bodizs R, Halasz P, Bagdy G (2002) Acute and long-term effects of the 5-HT2 receptor antagonist ritanserin on EEG power spectra, 
motor activity, and sleep: changes at the light-dark phase shift. Brain Res 943:105-111. CrossRef Medline

Kapás L, Obal F Jr, Book AA, Schweitzer JB, Wiley RG, Krueger JM (1996) The effects of immunolesions of nerve growth factor-receptive neurons by 192 IgG-saporin on sleep. Brain Res 712:53-59. CrossRef Medline

Kasahara T, Abe K, Mekada K, Yoshiki A, Kato T (2010) Genetic variation of melatonin productivity in laboratory mice under domestication. Proc Natl Acad Sci U S A 107:6412-6417. CrossRef Medline

Kawai K, Yokota N, Yamawaki S (1994) Effect of chronic tryptophan depletion on the circadian rhythm of wheel-running activity in rats. Physiol Behav 55:1005-1013. CrossRef Medline

Kramer A, Yang FC, Snodgrass P, Li X, Scammell TE, Davis FC, Weitz CJ (2001) Regulation of daily locomotor activity and sleep by hypothalamic EGF receptor signaling. Science 294:2511-2515. CrossRef Medline

Landolt HP, Wehrle R (2009) Antagonism of serotonergic 5-HT2A/2C receptors: mutual improvement of sleep, cognition and mood? Eur J Neurosci 29:1795-1809. CrossRef Medline

LeSauter J, Silver R (1999) Localization of a suprachiasmatic nucleus subregion regulating locomotor rhythmicity. J Neurosci 19:5574-5585. Medline

Lu J, Zhang YH, Chou TC, Gaus SE, Elmquist JK, Shiromani P, Saper CB (2001) Contrasting effects of ibotenate lesions of the paraventricular nucleus and subparaventricular zone on sleep-wake cycle and temperature regulation. J Neurosci 21:4864-4874. Medline

Lu J, Bjorkum AA, Xu M, Gaus SE, Shiromani PJ, Saper CB (2002) Selective activation of the extended ventrolateral preoptic nucleus during rapid eye movement sleep. J Neurosci 22:4568-4576. Medline

Marks GA, Speciale SG, Roffwarg HP (1989) Sleep state-specific neuronal activity in rat dorsal lateral geniculate nucleus is not altered by local serotonin and norepinephrine depletion. Exp Brain Res 74:402-410. Medline

Matsuki T, Nomiyama M, Takahira H, Hirashima N, Kunita S, Takahashi S, Yagami K, Kilduff TS, Bettler B, Yanagisawa M, Sakurai T (2009) Selective loss of $\mathrm{GABA}(\mathrm{B})$ receptors in orexin-producing neurons results in disrupted sleep/wakefulness architecture. Proc Natl Acad Sci U S A 106: 4459-4464. CrossRef Medline

Maywood ES, O’Neill J, Wong GK, Reddy AB, Hastings MH (2006) Circadian timing in health and disease. Prog Brain Res 153:253-269. CrossRef Medline

Mieda M, Sakurai T (2011) Bmall in the nervous system is essential for normal adaptation of circadian locomotor activity and food intake to periodic feeding. J Neurosci 31:15391-15396. CrossRef Medline

Mistlberger RE (2005) Circadian regulation of sleep in mammals: role of the suprachiasmatic nucleus. Brain Res Brain Res Rev 49:429-454. CrossRef Medline

Mistlberger RE, Bossert JM, Holmes MM, Marchant EG (1998) Serotonin and feedback effects of behavioral activity on circadian rhythms in mice. Behav Brain Res 96:93-99. CrossRef Medline

Miyamoto H, Katagiri H, Hensch T (2003) Experience-dependent slowwave sleep development. Nat Neurosci 6:553-554. CrossRef Medline

Monti JM, Jantos H (2008) The roles of dopamine and serotonin, and of their receptors, in regulating sleep and waking. Prog Brain Res 172: 625-646. CrossRef Medline

Morin LP, Allen CN (2006) The circadian visual system, 2005. Brain Res Rev 51:1-60. CrossRef Medline

Morin LP, Blanchard J (1991) Depletion of brain serotonin by 5,7-DHT modifies hamster circadian rhythm response to light. Brain Res 566: 173-185. CrossRef Medline

Nakamaru-Ogiso E, Miyamoto H, Hamada K, Tsukada K, Takai K (2012) Novel biochemical manipulation of brain serotonin reveals a role of serotonin in the circadian rhythm of sleep-wake cycles. Eur J Neurosci 35:1762-1770. CrossRef Medline

Nakamura TJ, Nakamura W, Yamazaki S, Kudo T, Cutler T, Colwell CS, Block GD (2011) Age-related decline in circadian output. J Neurosci 31:10201-10205. CrossRef Medline

Nakamura W, Honma S, Shirakawa T, Honma K (2002) Clock mutation lengthens the circadian period without damping rhythms in individual SCN neurons. Nat Neurosci 5:399-400. CrossRef Medline

Nakamura W, Yamazaki S, Nakamura TJ, Shirakawa T, Block GD, Takumi T (2008) In vivo monitoring of circadian timing in freely moving mice. Curr Biol 18:381-385. CrossRef Medline

Nishihara M, Sano A, Kimura F (1994) Cessation of the electrical activity of gonadotropin-releasing hormone pulse generator during the steroidinduced surge of luteinizing hormone in the rat. Neuroendocrinology 59:513-519. CrossRef Medline

Ohta H, Yamazaki S, McMahon DG (2005) Constant light desynchronizes mammalian clock neurons. Nat Neurosci 8:267-269. CrossRef Medline

Ono T, Sasaki K, Shibata R (1987) Diurnal- and behaviour-related activity of ventromedial hypothalamic neurones in freely behaving rats. J Physiol 394:201-220. Medline

Phan TX, Phan TH, Chan GC, Sindreu CB, Eckel-Mahan KL, Storm DR (2011) The diurnal oscillation of MAP (mitogen-activated protein) kinase and adenylyl cyclase activities in the hippocampus depends on the suprachiasmatic nucleus. J Neurosci 31:10640-10647. CrossRef Medline

Popa D, Léna C, Fabre V, Prenat C, Gingrich J, Escourrou P, Hamon M, Adrien J (2005) Contribution of 5-HT2 receptor subtypes to sleepwakefulness and respiratory control, and functional adaptations in knock-out mice lacking 5-HT2A receptors. J Neurosci 25:11231-11238. CrossRef Medline

Portas CM, McCarley RW (1994) Behavioral state-related changes of extracellular serotonin concentration in the dorsal raphe nucleus: a microdialysis study in the freely moving cat. Brain Res 648:306-312. CrossRef Medline

Ralph MR, Foster RG, Davis FC, Menaker M (1990) Transplanted suprachiasmatic nucleus determines circadian period. Science 247:975-978. CrossRef Medline

Ruby NF, Hwang CE, Wessells C, Fernandez F, Zhang P, Sapolsky R, Heller HC (2008) Hippocampal-dependent learning requires a functional circadian system. Proc Natl Acad Sci U S A 105:15593-15598. CrossRef Medline

Saper CB, Lu J, Chou TC, Gooley J (2005) The hypothalamic integrator for circadian rhythms. Trends Neurosci 28:152-157. CrossRef Medline

Saper CB, Fuller PM, Pedersen NP, Lu J, Scammell TE (2010) Sleep state switching. Neuron 68:1023-1042. CrossRef Medline

Schwartz WJ, Gross RA, Morton MT (1987) The suprachiasmatic nuclei contain a tetrodotoxin-resistant circadian pacemaker. Proc Natl Acad Sci U S A 84:1694-1698. CrossRef Medline

Silver MA, Stryker MP (1999) Synaptic density in geniculocortical afferents remains constant after monocular deprivation in the cat. J Neurosci 19: 10829-10842. Medline

Silver R, LeSauter J, Tresco PA, Lehman MN (1996) A diffusible coupling signal from the transplanted suprachiasmatic nucleus controlling circadian locomotor rhythms. Nature 382:810-813. CrossRef Medline

Smale L, Michels KM, Moore RY, Morin LP (1990) Destruction of the hamster serotonergic system by 5,7-DHT: effects on circadian rhythm phase, entrainment and response to triazolam. Brain Res 515:9-19. CrossRef Medline

Takahashi JS, Hong HK, Ko CH, McDearmon EL (2008) The genetics of mammalian circadian order and disorder: implications for physiology and disease. Nat Rev Genet 9:764-775. CrossRef Medline

Takahashi K, Lin JS, Sakai K (2009) Characterization and mapping of sleepwaking specific neurons in the basal forebrain and preoptic hypothalamus in mice. Neuroscience 161:269-292. CrossRef Medline

Tischkau SA, Mitchell JW, Pace LA, Barnes JW, Barnes JA, Gillette MU (2004) Protein kinase G type II is required for night-to-day progression of the mammalian circadian clock. Neuron 43:539-549. CrossRef Medline

Welsh DK, Takahashi JS, Kay SA (2010) Suprachiasmatic nucleus: cell autonomy and network properties. Annu Rev Physiol 72:551-577. CrossRef Medline

Wulff K, Gatti S, Wettstein JG, Foster RG (2010) Sleep and circadian rhythm disruption in psychiatric and neurodegenerative disease. Nat Rev Neurosci 11:589-599. CrossRef Medline

Yamaguchi S, Isejima H, Matsuo T, Okura R, Yagita K, Kobayashi M, Okamura H (2003) Synchronization of cellular clocks in the suprachiasmatic nucleus. Science 302:1408-1412. CrossRef Medline

Yamazaki S, Kerbeshian MC, Hocker CG, Block GD, Menaker M (1998) Rhythmic properties of the hamster suprachiasmatic nucleus in vivo. J Neurosci 18:10709-10723. Medline

Zant JC, Leenaars CH, Kostin A, Van Someren EJ, Porkka-Heiskanen T (2011) Increases in extracellular serotonin and dopamine metabolite levels in the basal forebrain during sleep deprivation. Brain Res 1399:40-48. CrossRef Medline 